\title{
O LUGAR E AS ESCALAS E SUAS DIMENSÕES HORIZONTAL E VERTICAL NOS TRABALHOS PRÁTICOS: IMPLICAÇÕES PARA O ENSINO DE CIÊNCIAS E EDUCAÇÃO AMBIENTAL*
}

\section{Place and scales with vertical and horizontal dimensions in pratical work: implications for science teaching and environmental education}

Maurício Compiani ${ }^{1}$

\begin{abstract}
Resumo: A Geologia apresenta epistemologia e prática escolar peculiares, em que a categoria de lugar e as escalas de observação, com suas dimensões horizontal e vertical, trazem implicações novas para o ensino de ciências e educação ambiental. No ensino de ciências, enfocar o lugar e o ambiente (o global) traz outro olhar para os trabalhos de campo. A escala é problematizada como estratégia de aproximação e apreensão do real. Duas experiências, no Brasil e na Venezuela, são apresentadas para mostrar a temática do trabalho.
\end{abstract}

Palavras-chave: Ensino de ciências. Educação ambiental. Trabalhos de campo. Lugar. Escalas de observação.

\begin{abstract}
Geology has a particular epistemology and school practice in which observations with horizontal and vertical dimensions within particular places and scales have new implications for science teaching and environmental education. In the science teaching, focusing on the place and the global environment bring other views to field work. Scale is seen as a strategy of approximation and a way of understanding reality. Two experiences in Brazil and Venezuela present these conceptions.
\end{abstract}

Key words: Science education. Environment education. Fieldwork. Place. Scale of observation.

\footnotetext{
*Elaborado a partir de Compiani (2005a), incorporando sugestões dos debates na sessão de comunicação oral.

${ }^{1}$ Doutor em Educação; docente, departamento de Geociências Aplicadas ao Ensino, Instituto de Geociências, Universidade Estadual de Campinas (Unicamp). Campinas, SP. < compiani@ige.unicamp.br>
}

Instituto de Geociências, Unicamp

Departamento de Geociências Aplicadas ao Ensino

Caixa Postal 6152

Campinas, SP

29

13.083-970 


\section{Introdução}

O artigo se enquadra nas discussões sobre trabalhos práticos no ensino de Ciências, trazendo a contribuição do ensino de Geologia/Geociências para o debate. Há possibilidades de diálogos frutíferos com o enfoque Ciência/Tecnologia/Sociedade/Ambiente (CTSA), no ensino de Ciências, e com a educação ambiental, bem como com discussões curriculares mais gerais do campo da educação acerca do papel do lugar, local nos itinerários curriculares locais/ globais. São possibilidades, intenções de diálogos, por isso vários autores importantes não foram citados.

Visões epistemológicas de ciências e visões pedagógicas da prática escolar influenciam as escolhas - pelo professor - de métodos de ensino/aprendizagem, este tendo claro ou não. Como ensinar? Nem a ciência, nem a filosofia da ciência, nem os estudos de metodologia do ensino fornecem um método infalível sobre como proceder. A teoria da ciência não contém um meio de ensinar e aprender, e não é apenas pelo método científico que se pode adquirir de modo significativo o conhecimento científico. Experiências de aprendizagem não devem ser uma tentativa de imitar o método científico. E há uma crença de que método científico é sinônimo de experimentação. Existe uma série de trabalhos que podem ser práticos e não envolver experimentação, tais como: uso de computador, análise de estudos de casos, entrevistas, debates, feitio de modelos, maquetes, vídeo, seqüência de slides e, especificamente, no caso da Geologia, os trabalhos de campo.

Os trabalhos de campo têm importância vital. Neles, há uma série de habilidades/ atitudes envolvidas que seguem um padrão quase 'artístico' e 'engenhoso' e, por isso, complexas de serem ensinadas. Em Geologia, os trabalhos de campo podem iluminar e colaborar para a redefinição dos trabalhos práticos no ensino de ciências e educação ambiental.

Os trabalhos de campo em Geologia apontam para noções diferentes do empírico. Neles há uma grande ênfase na qualidade das observações na natureza, exercitando percepção/abstração, descrição e expressões gráficas, notadamente o desenho. Na busca de amostragem em campo, os estudantes passam por um conjunto de ações, que se inicia concomitantemente ao estudo pela literatura sobre a região, observação de mapas topográficos, fotos aéreas e imagens de satélite. Aqui já começa uma certa procura de texturas e padrões das imagens que potencialmente indicam características, fenômenos da região, para os posteriores trabalhos de campo.

No campo, é fundamental discernir padrões que não requerem nenhuma instrumentação cara, complexa, mas somente lápis e um bloco de papel: o domínio das rochas pode ser obtido pela experiência simples do desenho (LEVESON, 1988). O autor justifica suas idéias: para desenhar ou criar um esquema, deve-se olhar, ver e tomar decisões. Uma imagem desenvolve-se. Existe contínuo questionamento e resposta, avaliação e reavaliação. Quão grande é isto comparado com aquilo? Os contatos são bruscos ou gradacionais? Contínuos ou interrompidos? Paralelos ou interceptados? Uma camada que gradualmente desaparece, reaparece em outro lugar? Onde? É a mesma? Foi mudada? Como as estruturas internas relacionam-se com os corpos externos? Observar/desenhar leva à aprendizagem do ver, a visão torna-se acurada. Em campo, como decidir por amostragens representativas, que inclusive podem ser traduzidas por gráficos? Ou, como elaborar perfis e blocos diagramas representativos de uma região geológica? O problema em questão orientará o uso de escalas de observação para as 
comparações e correlações que, juntamente com noções de homogeneidade e heterogeneidade, definirão as amostragens e os modelos a serem feitos. Isso não ocorre sem o apoio de colegas para as interpretações e orientações do professor. As observações, desenhos, coletas, entrevistas e outras formas estendem-se no tempo e em diferentes pontos para, dentro de uma escala de observação pré-estipulada, reunir informações da região em estudo, atividades distribuídas entre os colegas de pesquisa.

Em Geologia, trabalham-se com gigantescas escalas espaciais e temporais e observação indireta de vários fenômenos, por exemplo, os modelos sísmicos do interior da Terra ou os caminhos da água subterrânea. Com isso, pode-se auxiliar os estudantes no exercício de causas e efeitos mais distantes do seu dia-a-dia - temporal e espacialmente - e exercitar a explicação de fenômenos com causas diversas de modo a, progressivamente, ir construindo um raciocínio mais complexo, diferente da causalidade linear e simples ${ }^{2}$. Ela trabalha com produtos, objetos que resistiram às erosões e tectonismo, vestígios de processos passados. Sua lógica é do efeito para a causa. A Geologia é ciência histórica, diferentemente da lógica da causa para o efeito, muito característica das ciências físicas e químicas. Seu conceito de experiência é calcado na observação de contextos, na qualidade das observações e interpretações de formas fixadas de produtos de processos passados, codificando-as, espaço-temporalmente, no desvendar da história da Terra. Mais à frente, discutindo as práticas, mostraremos um pouco melhor o modo de cognição dos geólogos, aprofundado em Compiani (1996a e b).

$\mathrm{O}$ uso dos trabalhos de campo por professor e alunos pode orientar o questionamento sobre as velhas disciplinas, aperfeiçoando novas linhas teóricas na tentativa de entendimento mais amplo das relações entre local/global e entre disciplinas escolares científicas e a transversalidade (entendida como educação não disciplinar, conforme defendida por Gallo, 2000). É um olhar, até então quase inexistente no ensino de ciências, para a categoria geocientífica "lugar" como o locus de ligação com o todo, uma interação sutil da particularidade e da generalização. É um olhar para o ambiente, que entrou em pauta para todas as ciências a partir da crise socioambiental, antiga na história da humanidade, mas inescapável de ser enfrentada neste novo milênio.

\footnotetext{
2 Normalmente, e em qualquer trabalho de campo, deparamo-nos com muitos fenômenos geológicos para os quais existem várias explicações causais, o que, em geologia, recebe o nome de fenômenos convergentes. Uma das práticas mais utilizadas para tratar os fenômenos convergentes é o "método das múltiplas hipóteses de trabalho", proposto por Chamberlim (1931), cujo objetivo é ter à mão "toda explicação racional do fenômeno e desenvolver toda hipótese sustentável sobre sua causa e origem” (p. 160). "O método (...) desenvolve um pensamento próprio, que pode ser designado como o 'hábito do pensamento paralelo', ou do 'pensamento complexo'. É contradistinto da ordem linear de pensamento, que é necessariamente cultivada na linguagem (verbal) e na matemática, porque (nestas) seus modos de pensar são lineares e sucessivos” (p. 164). Isto torna bastante enriquecedor o trabalho científico com a geologia, já que propicia ao aluno maior capacidade de executar tarefas mais complexas, que exigem combinação de múltiplas variáveis, o que facilita a maturação cognitiva - um dos alvos do ensino - a partir da elaboração e do contraste das várias hipóteses explicativas da complexidade de causas.
} 
Esse olhar vem sendo acompanhado pela valorização do ambiente no ensino de ciências que, após quase duas décadas tratando do enfoque Ciência, Tecnologia e Sociedade (CTS), de meados dos anos 1990 para cá passou a buscar construir um enfoque CTSA (acrescenta-se Ambiente). Enfocar o lugar e o global/ambiente, traz um olhar, pouco usual no ensino de ciências, para os trabalhos de campo. A história das sociedades é incompleta sem uma compreensão da história ambiental.

Talvez pela pouca compreensão da concepção de escalas geográficas e geológicas, uma série de projetos de ensino de educação ambiental, principalmente voltados para os problemas urbanos, ainda trata somente dos problemas locais, sem derivar para os problemas globais. Normalmente, pratica uma simplificada contextualização, não enxergando que lugar e global são indissociáveis e apreendidos pela dialética contextualização/descontextualização e horizontalidade/verticalidade.

Como se pretende mostrar neste artigo, as escalas e suas dimensões horizontal e vertical são um método de abordagem - ênfase nos processos de obtenção de informação pois, dependendo da escala e do ponto de vista de quem está interpretando, um problema socioambiental terá diferentes perspectivas de enquadramento teórico e prático. De acordo com a problemática e escala, o lugar/parte e o global/todo se constituem diferentemente. É preciso formar cidadãos participativos que tenham um olhar interdisciplinar e saibam focar disciplinarmente para resolver alguns problemas e situações. Seria uma dialética do disciplinar com o interdisciplinar; um pensar local/globalmente e saber atuar local e globalmente (máxima dos movimentos ambientalistas com fortes implicações na educação ambiental). Mais ainda: cidadãos que saibam fazer mediações entre culturas, saberes acadêmicos e cotidianos, valores, interesses e imagens do futuro.

O focar para a relação local/global aponta para a necessidade das metodologias de estudos do meio e trabalhos de campo. O trabalho de campo pode ser utilizado, no ensino, como estratégia em que todas as coisas podem tomar parte de um processo maior: o efeito holográfico. A idéia é enfrentar a dominante fragmentação do conhecimento, que bloqueia os mecanismos de análise de problemas reais ao não facilitar a relação de conceitos, procedimentos e de atitudes, trabalhados em diferentes disciplinas do currículo. Por meio das atividades de campo, a categoria geocientífica "lugar" é entendida como o locus de ligação com o todo, uma interação sutil da particularidade e da generalização. Assim, é possível sair do paradigma da causalidade tão enraizado no ensino de ciências e praticar um ensino mais contextualizado, situar espaço-temporalmente os fenômenos, ou seja: levar em conta o aspecto histórico dos fenômenos e, ao fazer isso, compreender a complexidade do contexto e causalidade de um fenômeno.

No rumo de um conhecimento escolar mais contextualizado, a Geologia tem grande contribuição para o ensino de ciências e educação ambiental, pois é uma ciência histórica da natureza, conforme aprofundado em Compiani (2005b, 1990).

As aulas tradicionais e o livro didático predominantes nas escolas são descontextualizados e centrados no enciclopedismo das definições. Quando há trabalhos práticos, estes são demonstrações ilustrando teorias já vistas. Ensinam-se repertórios e definições, informações, de modo geral, trabalhadas pelos professores de maneira isolada e fragmentada, refletindo a organização das informações divididas nas unidades e sub-unidades dos livros didáticos.

A escola, de certo modo, ignora a vida, pois idealiza um aluno abstrato, sem tempo e 
O lugar e as escalas e suas dimensões ...

sem espaço. O aluno real, em seu contexto, com sua experiência social e individual em sua localidade é ignorado. Por não ter um interlocutor real, a escola é incapaz de ocupar seu lugar de produção de conhecimentos gerados na interação entre o mundo cotidiano e o científico. Os alunos investigam somente quando resolvem problemas com a mente aberta. A postura de curiosidade e investigação pode ser propiciada pela mediação do professor. É preciso situar informações e dados em seu contexto para que adquiram sentido. Para ter sentido, a palavra necessita do texto, que é o próprio contexto, e o texto se constitui pelo contexto no qual se enuncia. Tudo isso reforça que se deve dar mais atenção à seqüência do trabalho pedagógico em sala de aula, no qual sejam considerados o acontecimento, a localidade, o contexto e o processo interativo. A sala de aula deve ser local de diálogo, compartilhamento, de complexidade, contextualização e solidariedade (ALVES e GARCIA, 2000). Trabalhos de campo e estudos do meio adquirem relevância como práticas pedagógicas nas escolas (PONTUSCHKA, 1993).

Em relatos analíticos de suas experiências num projeto de formação continuada para o Ensino Fundamental, com temas de geociências (COMPIANI et al., 2001), as professoras ressaltam que os estudos do meio: a) permitiram contato direto com a natureza e seus processos; b) foram o locus privilegiado para a integração de saberes prévios, informações adquiridas em sala e observações/dados obtidos no campo; c) remeteram à localidade e ao cotidiano dos alunos; e d) despertaram nos estudantes novo entusiasmo pelo aprender. Os trabalhos de campo foram um dos resultados metodológicos mais importantes do projeto, um dos 'instrumentais' mais poderosos para contextualizar o ensino, levando em conta o entorno da escola de modo amplo: socioambientalmente. Os resultados do projeto substanciam idéias desenvolvidas neste artigo.

\section{A escala e suas dimensões horizontal e vertical nos trabalhos de campo}

Iniciando a importância que é tratar o campo, citamos, com apoio de Ab'Saber (1991), questões necessárias para uma abordagem lugar/ambiente. Essa perspectiva exige método, noção de escala, boa percepção das relações entre tempo e espaço, entendimento da conjuntura social, conhecimentos sobre diferentes realidades regionais, culturas e diferentes códigos de linguagem adaptados às concepções prévias do alunado. Exige, sobretudo, respeitar e acreditar no valor da multiplicidade e diversidade dos vários "mundos" que coexistem nas sociedades. Implica exercício permanente de interdisciplinaridade e enfrentar questões cotidianas.

Os registros da história da Terra e da humanidade estão sempre espacial e temporalmente marcados. É na localidade que estão as marcas, os registros, que atestam o que existiu. O processo de reconstrução histórica por meio dos registros realça a relação de indexalidade. $O$ índice é um modo de relação entre o signo e seu referente, que remete ao contato ou à conexão física. $\mathrm{O}$ fóssil, a fotografia, o documento, a memória por meio da oralidade são índices: marcas daquilo que realmente existiu. Exercem a função de atestação (DUBOIS, 2000).

Segundo Kincheloe (1997), a atenção para o local traz o foco para o particular, mas num sentido que, contextualmente, baseia-se num entendimento maior do entorno e dos processos que o moldam. O sentido de local aguça o entendimento do contexto, do singular e histórico, e, conjugadamente, aguça o entendimento do abstrato, das propriedades, do generalizável. Enfim, a atividade de campo é o locus de constituição da dialética e do círculo herme- 
nêutico (vide FRODEMAN, 1995) entre as partes e o todo, o particular e o geral, o generalizável e o histórico. Esse caráter dialético realça a integração do todo (desenvolvimento histórico da Terra) e suas partes (processos, esferas constituintes, estruturas, formas fixadas etc.), e, também, o aspecto orgânico do conhecimento, já que a própria constituição da totalidade tem sua gênese e seu desenvolvimento histórico.

Os geógrafos trazem uma contribuição para a noção de escala assinalando que ela é mediadora da pertinência da ligação entre a coisa observada e o atributo a ela associado. Para Castro (1996), há variação dos atributos da grande para a pequena escala. Assim, a informação factual, os dados individuais ou desagregados, a valorização do vivido e a tendência à heterogeneidade são atributos de fenômenos observados na grande escala. Por sua vez, a informação estruturada, os dados agregados, a valorização do organizado e a tendência à homogeneização são atributos dos fenômenos observados na pequena escala. Os geólogos também trazem suas contribuições caminhando na mesma linha de Castro, apontando que em escalas diferentes de observação podem ser observadas informações qualitativamente diferentes sobre o mesmo objeto (LACREU, 1999). Bach et al. (1988) formulam uma proposta de metodologia de hierarquização das observações de campo em Geologia.

\begin{tabular}{|l|l|}
\hline \multicolumn{1}{|c|}{ HIERARQUIZAÇÃO } & \multicolumn{1}{c|}{ ATIVIDADES } \\
\hline $\begin{array}{l}1 \text { - Situação dentro de grandes } \\
\text { unidades geológicas e de relevo }\end{array}$ & Visão panorâmica da paisagem \\
\hline $\begin{array}{l}2 \text { - Situação do afloramento no } \\
\text { contexto da paisagem próxima }\end{array}$ & $\begin{array}{l}\text { Procurar obter conhecimentos dos elementos morfológicos da } \\
\text { paisagem para isolar unidades do relevo }\end{array}$ \\
\hline 3 - Visão de conjunto do afloramento & $\begin{array}{l}\text { Observação do afloramento a distância reconhecendo feições } \\
\text { geométricas, estrutura e disposição dos materiais }\end{array}$ \\
\hline 4 - Estudo em detalhe do afloramento & $\begin{array}{l}\text { Descrição e identificação de cada unidade litológica } \\
\text { reconhecendo as estruturas e contatos }\end{array}$ \\
\hline 5 - Estudo de amostra de mão & $\begin{array}{l}\text { Classificação dos tipos de rochas em função da identificação } \\
\text { de componentes texturais, minerais e/ou fósseis presentes }\end{array}$ \\
\hline
\end{tabular}

Quadro 1. Hierarquização das observações de campo.

(Adaptado de Bach et al., 1988)

Os locais, as regiões, o ambiente podem ser tratados a partir das dimensões horizontal e vertical. Suertegaray (1996), no âmbito da geografia, discute essas dimensões. A horizontalidade enfatiza as relações entre as partes e o todo, faz com que um fenômeno, objeto, aspecto seja contextualizado, situado espaço-temporalmente e comparado com outros a partir de sua localidade, acentuando-se as particularidades, singularidades e relações na busca de padrões. Aqui, a espacialidade é realçada. Em cada local pode-se desenvolver a respectiva historicidade, buscas de compreensão dos fenômenos em termos das causalidades situadas em um contexto. A verticalidade enfatiza o caráter processual dos fenômenos, das coisas. Observa 
O lugar e as escalas e suas dimensões ...

os diferentes contextos da horizontalidade, buscando explicá-los em conjunto ou conjuntos, em termos de propriedades, categorias: há um rumo para a descontextualização, para as generalizações, em que se 'apagam' tempo e espaço. Pode-se escrever:

- horizontalidade - local - particular/singular/histórico rumo à contextualização;

- verticalidade - global - geral/propriedade/generalização rumo à descontextualização.

É uma dialética da contextualização/descontextualização que gera consciência, compreensões, explicações, atitudes e ações mais reflexivas e críticas historicamente contextualizadas e situadas.

\section{Trabalhos de campo como metodologia de ensino}

Em relação ao ensino de Ciências/Geologia para o Ensino Médio, o campo - a natureza - significa o contato com objetos, fenômenos concretos, ambiente, ou seja: o contexto a partir do qual se criam situações e estratégias de aprendizagem. Adotando uma concepção mais abrangente de campo, ele passa a ser definido como o local das atividades voltadas para ensinar o método geral de conceber a história da Terra. Estas atividades estão inseridas num amplo e complexo processo de obtenção de informações na natureza e, potencialmente, seriam capazes de inter-relacionar o ambiente, a Geologia e a sociedade.

Sob a perspectiva educacional, o campo pode ser um fio condutor para uma disciplina - ou entre disciplinas -, que propicia o melhor desenvolvimento das peculiaridades da prática escolar científica e dos respectivos discursos escolares, podendo ser agente integrador da Geologia e outras ciências na construção de uma visão abrangente de natureza. Um dos pontos de partida é ver o campo como gerador de problemas, ótima situação de ensino problematizadora.

Como fio condutor de uma disciplina, o campo tem alto potencial para organizar e integrar uma ou mais disciplinas: parte-se de uma concepção de Geologia abrangente, integrase a cognição da natureza por meio da Geologia, ou método de conhecer a história geológica do planeta, e apreendem-se aspectos sociais e ambientais relacionados com esta ciência, propiciando integração com as outras ciências.

Se o currículo for um programa de atividades, a partir do qual os conhecimentos e as destrezas podem ser adquiridos e construídos, valores e atitudes, praticados, então, cresce de importância o campo (lugar/natureza) como fio condutor de uma disciplina ou de estudos do meio como ponto de partida e integrador de todo um ano letivo da escola média.

O campo é realçado por ser um excelente ambiente de ensino, que constitui o ensino/ aprendizagem por meio de diferentes papéis didáticos que possam ser adotados - como o ilustrativo, indutivo, motivador e investigativo (COMPIANI e CARNEIRO, 1993) -, juntamente com situações criativas, de métodos de resolução de problemas, atividades de motivação e sensibilização, de estudos de re-conhecimentos etc.

Este autor não concorda com os que defendem que o pensamento re-flexivo só tem lugar após certo acúmulo de informações. O campo é o lugar onde o conflito entre o mundo (o exterior) e as idéias (o interior) ocorre em toda sua intensidade: por isto é possível iniciar a construção de conhecimentos a partir dele, buscando informações e formulando conceitos porque lá está o/a lugar/natureza para ser observado/a e interpretado/a.

O campo, com suas paisagens, rochas, que guardam os vestígios dos processos natu- 
rais da história da Terra, torna-se uma situação problematizadora ideal para atividades práticoteóricas de aprendizagem. É o local onde, potencialmente, o estudante à procura de soluções para determinado problema pode observar as evidências, adquirir informações e interpretálas. É um excelente ambiente de ensino, e, se bem trabalhado, capaz de questionar a sala de aula tradicional, fechada por quatro paredes, com um professor em posição inacessível, distante. Existe um mito de que a sala de aula é natural. Aquele ambiente, as atividades que nele se desenvolvem, aquela disposição espacial que já se conhece desde criança e que pede determinado comportamento dos alunos... sempre foi assim. Todas as escolas são assim. Muitos professores pensam que o que interessa é o conteúdo de sua aula. Ledo engano este naturalismo da sala de aula.

O trabalho de campo que se propõe aqui evidencia a necessidade de uma crítica ao espaço da sala de aula e de romper com a monotonia e a posse exclusiva do discurso pelo professor. No campo, no afloramento, naquela "bagunça saudável", a geografia da ordem, das quatro paredes, cai por terra. As atividades de campo, numa concepção formativa, exacerbam a semelhança entre fazer e aprender ciência, não existindo quem ensina (transmite a verdade), mas, sim, os que aprendem fazendo uma ciência escolar. A propriedade do discurso por parte do professor na sala de aula tradicional é visivelmente quebrada, já que não existem o "palco" e a lousa. No campo, tudo pode prender a atenção do aluno, ser fonte de informações, de problemas e dados a serem trabalhados. Assim, no próprio campo, e nas posteriores aulas na sala, a questão da posse do saber somente pelo professor é desfocada, já que os alunos irão trabalhar com o material coletado, fazer novas pesquisas à procura de soluções para o problema assinalado pela excursão e deixar como marca da prática escolar a investigação, que estará permeando toda a atividade, desde a introdução até as conclusões.

O papel integrador do campo é ressaltado, primeiro, pela adoção de uma concepção de Geologia que absorva sua natureza de conhecimento sintético e histórico. Segundo Paschoale (1989), uma espécie de totalidade é seu ponto de partida (o planeta e suas várias camadas, como se apresenta agora) e a totalidade concebida como síntese de sua chegada (o desenvolvimento histórico da Terra). Depois, pela determinação epistemológica que o objeto de investigação mais imediato (a crosta) desempenha na prática científica e no ensino por meio das atividades de campo.

Assim, o papel integrador da Geologia aponta para seu princípio do atualismo, em que a utilização de todo e qualquer processo natural contemporâneo pode ser informativa para esta ciência. Isto significa que toda observação em campo de um fenômeno natural atual, ou mesmo a realização, em laboratórios, de processo similar, é informativo para a Geologia, na medida em que auxilia na identificação e decodificação das "formas fixadas" para a elaboração do processo histórico-geológico. Então, ao estudarem processos, aspectos ou partes individuais do planeta, biologia, geografia, física, química, entre outras, contribuem para o entendimento da história da Terra, porque a síntese procurada pela Geologia, por ser abrangente a todo o planeta, necessita da interação com as sínteses próprias dessas ciências.

Acreditamos que as idéias sobre o ensino de Geologia por meio do campo facilitam a estruturação abrangente, global e integrada da natureza e apontam, como fator relevante nas atividades de campo, sua própria característica, que propicia aos estudantes senso de integração dos processos da natureza, encorajando-os à percepção integrada, e não somente em partes individuais, da natureza. Lacreu (1999) faz interessante discussão sobre esse tema. 
O lugar e as escalas e suas dimensões ...

Não se pode perder de vista o papel do campo como fonte de conhecimento e suas conseqüências para o ensino como o local a ser enfatizado na construção de conhecimentos. Como prática, o campo representa tanto o local de onde se extraem as informações para as elaborações teóricas, como aquele onde tais teorias são testadas. Em suma, o trabalho de campo é, ao mesmo tempo, fonte de informações e de crítica da produção científico-geológica, peça fundamental para assimilação e construção de seus conceitos. É principalmente no campo que os geólogos testam suas hipóteses, reformulam ou complementam suas teorias. Portanto, a partir da observação da natureza, desenvolvem-se o raciocínio geológico e a capacidade criativa.

Todavia, isto não quer dizer que os alunos, por si só, construam todos os conhecimentos a partir do campo; nem que é possível - com uma breve reflexão e alguns poucos resultados práticos - derrubar uma teoria; e, muito menos, que se tenha a pretensão de simular a prática científica do geólogo por meio de saídas de um dia ao campo. Significa, porém, que somente por meio das atividades de campo aproximamo-nos da prática científica do geólogo, de uma atitude investigativa e atualista, não mascarando a complexidade desse conhecimento. O campo é essencial para o entendimento dos princípios e métodos desta prática científica por sinal fundamentais para compreendermos as possibilidades didáticas das atividades de campo para o Ensino Médio de ciências e educação ambiental -, fazer frente ao conhecimento escolar visto como acabado, fragmentado e descontextualizado, e propor atividades teóricopráticas calcadas em trabalhos de campo que enfoquem dialeticamente o local/global, o particular/geral e o generalizável/histórico.

\section{Trabalhos práticos de campo no lugar da escola}

Duas propostas de trabalho didático para o Ensino Médio, no Brasil e na Venezuela, servirão de exemplo para a discussão sobre o papel das escalas e suas dimensões, tema desta parte do trabalho. Uma, em ocupação de área pública no bairro "Jardim Ipanema”, cidade de São Paulo, Brasil. Há ali um assentamento de alto risco, por se tratar de vertente íngreme, com bota-fora (aterros), sinais de movimentos de massa e ravina profunda. A outra proposta é no Estado Vargas, na Venezuela, costa litorânea onde, em dezembro de 1999, ocorreu o desastre ambiental provocado por enchentes e corridas de lama e detritos (SÁNCHEZ, 2000).

No Brasil, as práticas escolares foram propostas para a disciplina "Ciências da Natureza e Matemática e suas tecnologias". Na Venezuela, para a disciplina "Ciencias de la Tierra" (naquele país existe a Licenciatura em Ciências da Terra, com a respectiva disciplina no Ensino Médio). A proposta didática envolveu a resolução de problemas por meio de estudo de caso. O tema do estudo de caso foi "desastres geológicos e suas causas sócio-ambientais".

No Brasil, o escorregamento não havia acontecido, mas uma série de evidências indicava que qualquer período mais chuvoso poderia deflagrar o processo: era uma região de risco geológico iminente. Já na Venezuela, o desastre era acontecido.

Nas duas situações educacionais houve três etapas de atividades: sala de aula, campo e sala de aula. $\mathrm{Na}$ primeira etapa em sala de aula trabalhavam-se textos jornalísticos, com intenção de formular conjecturas e hipóteses sobre o acidente geológico. Na Venezuela, por ser desastre já acontecido em 1999 e em outras épocas, incentivavam-se comparações entre o 
presente (acontecimento recente) e o passado, também com fotos aéreas. No Brasil, os textos jornalísticos sobre deslizamentos ocorridos em outras áreas do país serviam para os alunos formarem uma noção sobre o que a mídia veicula sobre deslizamento, suas causas e conseqüências (NEWERLA, 1999).

A discussão iniciava com uma pergunta: "O que a midia prioriza noticiar sobre esse assunto, que sempre no verão e periodo de chuvas abala várias regiões do país?'. Havia distorções e omissões importantes, que o trabalho de campo e posteriores atividades em sala iriam colocar em xeque. $\mathrm{Na}$ mídia, por exemplo, nenhuma referência era feita à possibilidade de existir articulação entre degradação ambiental e injustiça social.

$\mathrm{Na}$ etapa de campo, um problema orientava as atividades: "Quais são os riscos a que os moradores do Jardim Ipanema podem estar submetidos?". As atividades de campo eram de caráter indutivo (COMPIANI e CARNEIRO, 1993), de um dia de duração, organizadas a partir das escalas de observação (Quadro 1): paisagem da favela; por dentro da favela, corredores, vielas, erosões etc; e dados socioeconômicos dos favelados, com seus barracos e moradores. O ponto mais alto do relevo (como se pode ver na Figura 1) era o primeiro contato que perceptivamente enquadrava pelos olhos toda a região-problema. Para essa escala de observação, obtinham-se informações da relação entre ocupação e encosta, distribuição dos barracos na encosta e grandes feições de erosão, conforme a foto da região:

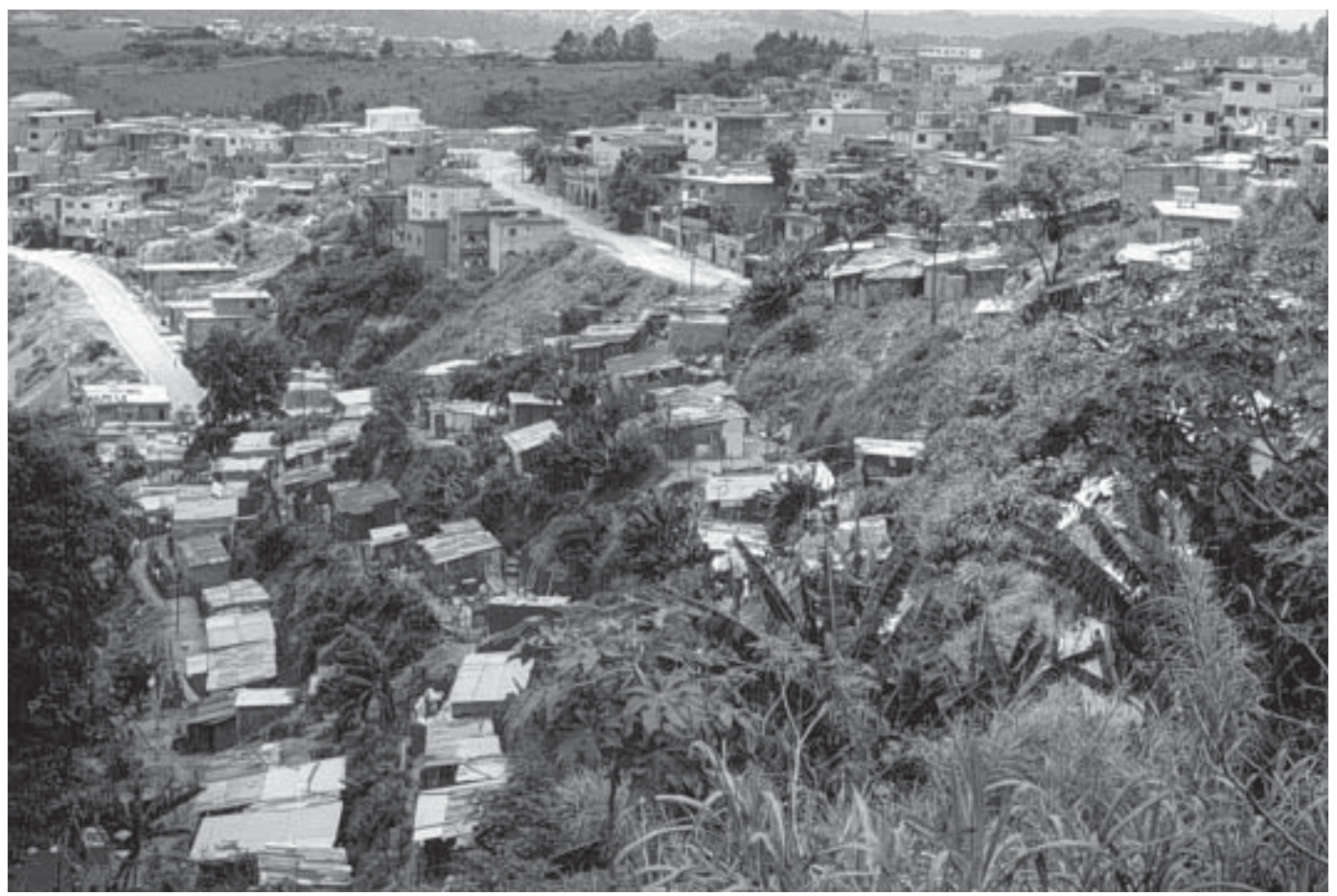

Figura 1. Foto de uma encosta ocupada por casas com população de baixa renda, Jardim Ipanema, São Paulo, SP, Brasil. 
O lugar e as escalas e suas dimensões ...

Passando para outra escala maior, que foi percorrer todos os cantos da favela, buscaram-se evidências dos riscos para as moradias, tais como: degraus, evidenciando possibilidade de escorregamento (num tempo humano e indicando uma cognição da Geologia, os degraus são evidências de um processo passado, efeito que aponta para a causa: início de deslizamento), taludes verticais, lixo e saída de águas servidas que se somavam para ocorrência dos escorregamentos. Depois, passou-se para uma escala mais próxima, por exemplo, descrevendo as casas. Aqui entram de dados socioeconômicos até ideologias, desejos etc. Havia preocupação em caracterizar as evidências de risco para discutir posteriormente medidas de mitigação. Essa intenção social e pedagógica fez com que, no trabalho de campo, fossem incluídas entrevistas com os habitantes e contatos com líderes do bairro, atividade didática não muito comum em trabalhos de campo em Geologia. Intencionalmente buscou-se incluir o contato com os grupos sociais ambientalmente desvaforecidos, entrevistas que seriam confrontadas com as versões da mídia. Essa intenção levou à realização de perfis pouco comuns em Geologia, como o da Figura 2, que descreve detalhes de um ponto, incluindo não só o substrato físico, como, também, os dados sociais. Materializa-se uma concepção de ciência geológica histórica, incluindo o homem como um dos agentes dos processos históricos da Terra (COMPIANI, 2005b; PASCHOALE, 1989).

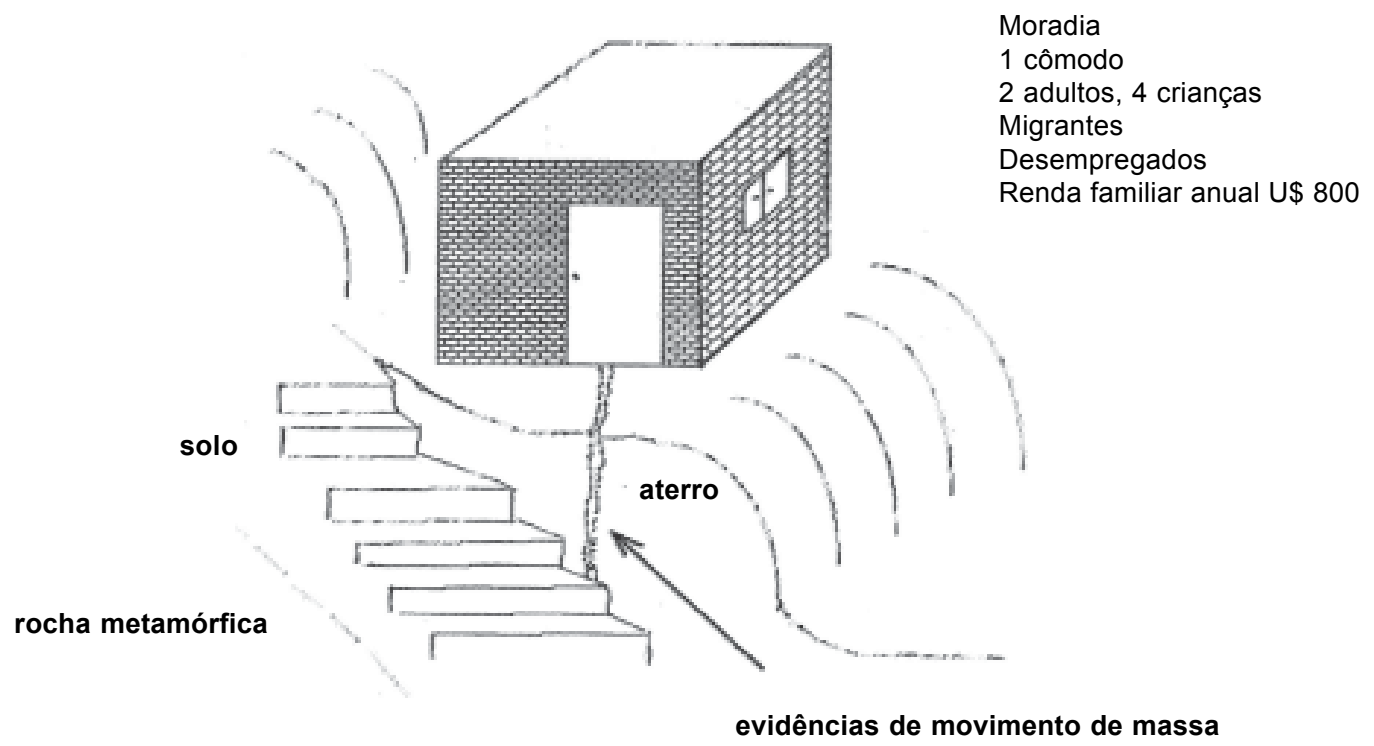

Figura 2. Um perfil tipo de uma encosta ocupada por casas com população de baixa renda, Jardim Ipanema, São Paulo, SP, Brasil. 
De volta à sala de aula foram feitos os chamados trabalhos de escritório: organizar as fotos, o mapa da região visitada com plotagem dos pontos com descrição, desenhos, croquis, elaboração de perfis da região, categorizar as entrevistas para posteriores discussões que, de algum modo, com a mediação do professor, levaram à construção da Figura 3. Já durante a construção da Figura 3 pôde-se trabalhar a horizontalidade e verticalidade de fenômenos em outras partes do mundo. No nosso caso, utilizamos o exemplo da Venezuela e vice-versa (o desastre ambiental na Venezuela foi discutido com slides, um vídeo e notícias de jornais).

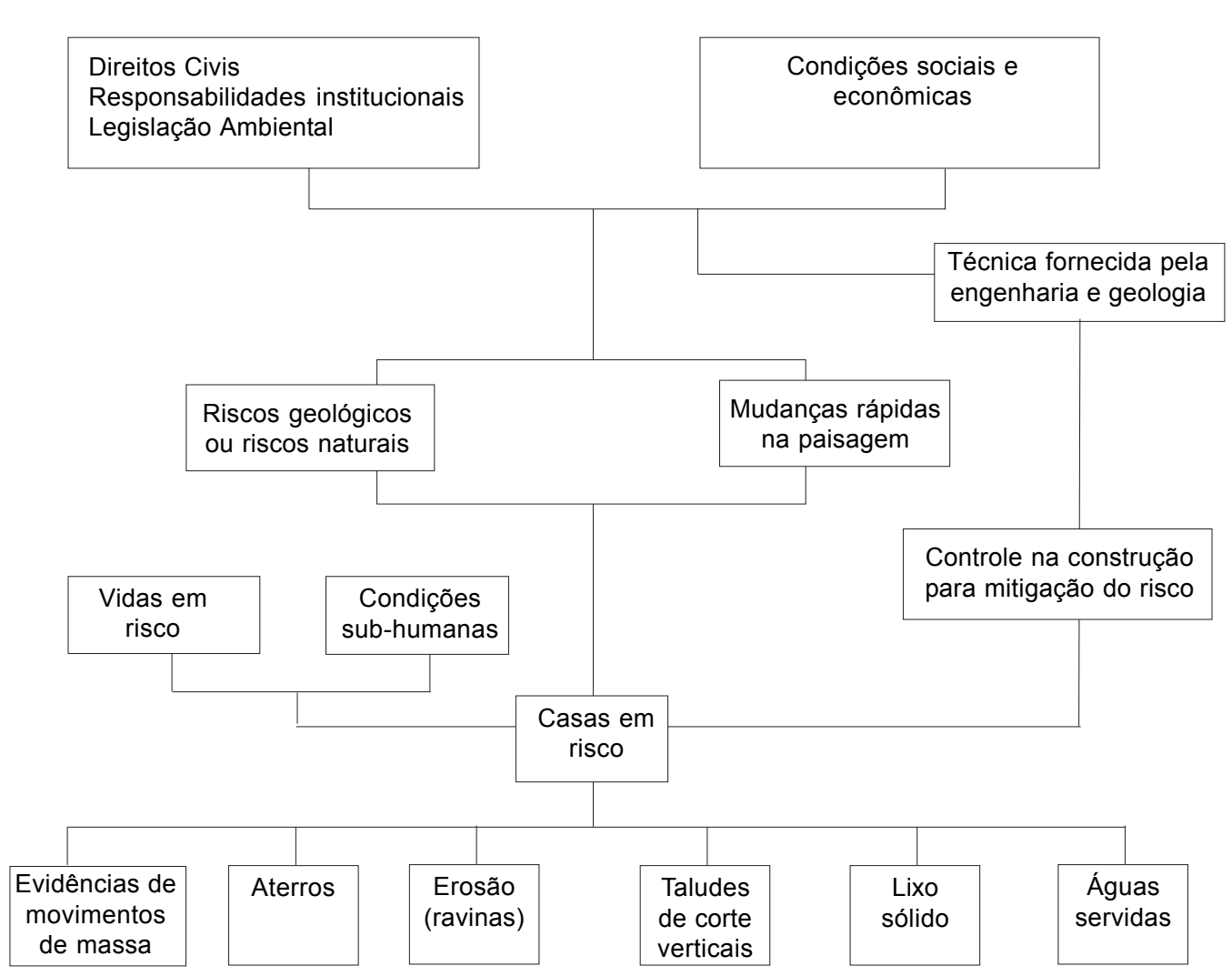

Figura 3. A organização de conceitos relacionados à estruturação conceitual do tema moradia no trabalho escolar feito no Jardim Ipanema, São Paulo, SP, Brasil.

Horizontalmente foram comparadas as duas espacialidades e os fenômenos respectivos. No Brasil, o Jardim Ipanema assenta-se sobre aterros sobre rochas metamórficas do proterozóico médio e o tipo de ocupação em favelas pela população de baixa renda transformou o lugar em zona de risco iminente de deslizamentos no período chuvoso. 
No Estado Vargas, faixa litorânea com ocupação urbana típica de classe média, e no alto das montanhas, com chácaras de lazer ou pequenos sítios, em região pertencente ao sistema montanhoso da Cordilheira do Caribe, ocorreu, em dezembro de 1999, o grande desastre ambiental.

Nos dois locais, o entendimento do risco das moradias no Brasil e do acidente geológico na Venezuela não é conseguido somente pela horizontalidade, observação e discussão do local. Necessita da dimensão da verticalidade, que aprofunda as causas comuns e específicas dos dois lugares. Horizontalidade e verticalidade necessitam dos trabalhos de campo, no qual são enfocados os processos da dinâmica superficial e suas interações com a geomorfologia (o modelado atual reflete a história dos processos de interface entre a dinâmica interna e externa) e com a urbanização desordenada e acelerada como causadores de acidentes geológicos. Aprofunda-se a compreensão da brusca mudança de paisagem e do risco geológico dessas regiões pesquisando-se as principais causas da instabilidade de encostas decorrentes da ação humana. As entrevistas feitas, somadas a leituras e discussões propostas pelo professor, possibilitaram maior compreensão das dimensões socioeconômicas indicadas na verticalização proposta na Figura 3, que parte dos fenômenos observados (lixo, degraus de abatimento etc), passando pela compreensão de moradias em risco e risco ambiental, chegando aos direitos civis e responsabilidades institucionais. Para uma compreensão das razões que levam as populações a ocuparem áreas de risco são interessantes as discussões já existentes na literatura sobre 'justiça ambiental', 'sociedade de risco' etc (ver, por exemplo, Acselrad, 2002).

Os mapas conceituais das duas regiões (figuras 3 e 4) são um exercício de horizontalidade e verticalidade e refletem as diferenças nos fenômenos e nas intenções pedagógicas para cada lugar.

No campo, e em sala de aula, exercitando a idéia de enfoque globalizador-integrador (ZABALA, 1989) com o conceito tempo avançou-se muito a dimensão da verticalidade e, por conseguinte, as causas e conseqüências dos fenômenos socioambientais envolvidos. A utilização das escalas de tempo dos ciclos de transformação do Sistema Terra (DA COSTA e INDA, 1992) levou a desenvolver a "escala" de tempo dos processos dos dois lugares. Chegou-se à compreensão de que a população assentou-se sobre terrenos metamórficos que foram formados por processos de duração extremamente longa (10 - 1000 milhões de anos). Em ambas as regiões houve e há intemperismo químico extensivo formado por processos de longa duração (10 - 100 até alguns milhões de anos), constituindo os perfis de solo e profundos mantos de intemperismo, estes fontes de material para as corridas de lama na Venezuela. Processos de duração média (séculos a poucos milhares de anos) formaram os perfis de solo locais que, no caso brasileiro, foram soterrados por aterros e, na Venezuela, sofriam intenso uso nas partes altas da Cordilheira, processos humanos caracterizados como de duração curta (anos, vários anos e décadas), que geram grandes mudanças do ambiente (vale lembrar que a formação da camada de húmus do solo é de duração curta). De maior impacto ambiental são os processos de duração muito curta (meio dia, dias e semanas), produzidos pela atividade humana. No Brasil, cortes verticais de taludes, despejo de águas servidas, fossas negras, depósitos de lixo sólido e entulhos estavam provocando a saturação do lençol freático, erosões e pequenos abatimentos do solo. Na Venezuela, represamentos, desmatamentos e intensas chuvas sem curvas de nível intensificaram as erosões. As chuvas, na Venezuela, geraram processos que caracterizamos como de duração extremamente curta (segundos, minutos e horas): 
Compiani, M.

escorregamentos, corridas de lama e detritos, alteração do modelado (a linha de costa na Venezuela na foz dos rios foi aumentada em dezenas de metros, formando leques de lama e detritos), perdas humanas, culturais e econômicas etc.

Os trabalhos de campo, as atividades de escritório, as leituras de textos e jornais, as discussões em sala de aula, atividades com o tema gerador tempo e a elaboração de mapas conceituais mostraram que a vida local entrou na escola mediada por professor e alunos. $\mathrm{O}$ lugar, com suas escalas e dimensões, foi reconhecido e tematizado.

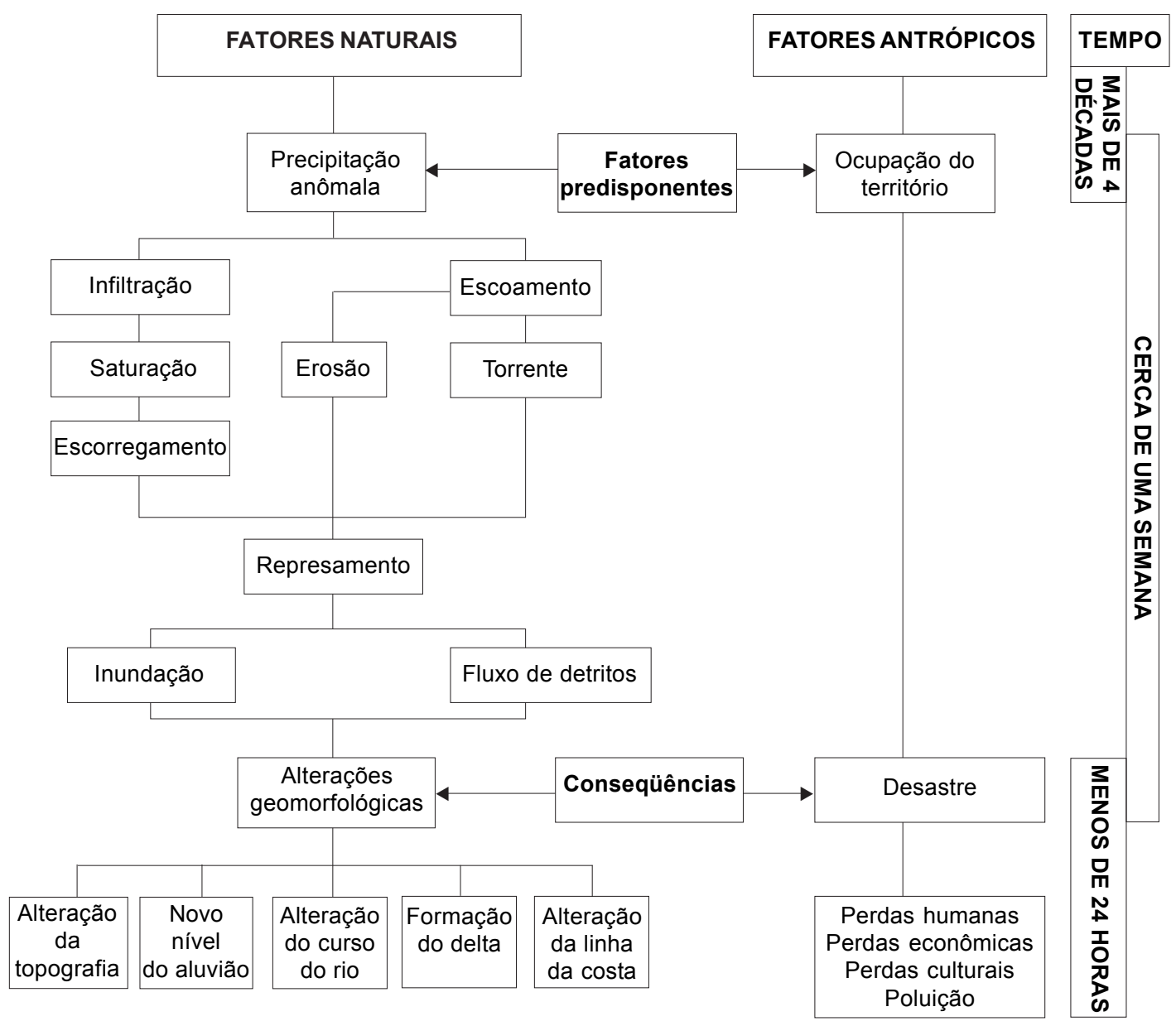

Figura 4. Conceito estruturante tempo na síntese dos eventos ocorridos no Estado Vargas, Venezuela, em dezembro de 1999. 
O lugar e as escalas e suas dimensões ...

\section{Idéias finais}

Temas presentes no cotidiano da comunidade local podem e devem ser tratados pelos professores nas escolas. O aprofundamento de conhecimentos em relação a aspectos tecnológicos e problemas sócio-ambientais que tenham implicações diretas na vida local auxilia a compreender os problemas a serem enfrentados pela sociedade, indústria, por populações organizadas etc. Ao analisarem a complexidade político-social e os problemas ambientais de determinada situação, os alunos percebem as dificuldades que cercam as decisões sobre as soluções do problema, bem como as relações dentro de uma comunidade, o que favorece a individualidade de opiniões e incentiva opiniões divergentes para o diálogo de diversos procedimentos a serem discutidos e, democraticamente, adotados.

Ao trabalhar os impactos ambientais provocados pelo descontrole do crescimento urbano acelerado, força-se a necessária relativização do papel da ciência e da tecnologia na resolução de problemas do dia a dia, pois fica evidente que os problemas ambientais são antes de outra coisa políticos - e isto se contrapõe à crença positivista de que a ciência é universalmente aplicável e eficaz (cientificismo). Essa visão oculta, por exemplo, a possibilidade de existir articulação entre degradação ambiental e injustiça social. Perante um ensino que tem fomentado a passividade, propõem-se a construção ativa de conhecimentos, ação, participação e tomada de decisões na solução de problemas que têm implicações políticas, sociais e ambientais.

Essas experiências têm levado a formular questões de pesquisa para o ensino de ciências e educação ambiental. Contexto chama atenção para localidade e lugar. Em se tratando da localidade - em parte devido ao uso nacional dos livros e, em parte, devido à crença equivocada de que se devem conhecer os conceitos genéricos e que estes são diretamente aplicáveis à localidade -, justamente o lugar não faz parte do escopo dos livros (que reúnem os conteúdos tal como fazem os almanaques, que priorizam temas gerais e curiosidades) e, por conseguinte, das aulas nas escolas. Ao reverso disso, estamos testando a aprendizagem contextualizada, na qual o aluno mobiliza competências para solucionar problemas devidamente contextualizados, de maneira a ser capaz de transferir essa capacidade de resolução de problema para outros contextos e desenvolver compreensão mais política e ideológica das relações local/ambiente. 
Compiani, M.

\section{Referências}

AB'SABER, A. N. (Re)conceituando educação ambiental. Rio de Janeiro: CNPQ/ MAST, 1991. (folder)

ALVES, N.; GARCIA, R. L. (Orgs.). O sentido da escola. 2. ed. Rio de Janeiro: DP\&A, 2000.

ACSELRAD, H. Justiça ambiental e construção social do risco. In: ENCONTRO DA ASSOCIAÇÃO BRASILEIRA DE ESTUDOS POPULACIONAIS, 13., 2002, Ouro Preto. Anais..., Ouro Preto, 2002. 1 CD-ROM

BACH, J.; BRUSI, D.; DOMINGO, M.; et al. Propuesta de una metodología y jeararquización de las observaciones del trabajo de campo en geología. Revista Henares, Henares, n. 2, p. 319-325, 1988.

CASTRO, I. E. O problema da escala. In: CASTRO, I. E.; GOMES, P. C. C.; CORREAA, R. L. (Orgs.). Geografia: conceitos e temas. Rio de Janeiro: Bertrand Brasil, 1995. p. 117-140.

CHAMBERLIN, T. C. The metod of multiple working hypotheses. The Journal of Geology, Chicago, n. 1, p. 155-165, 1931.

COMPIANI, M. O lugar e as escalas e suas dimensões horizontal e vertical nos trabalhos práticos geológicos - implicações para o ensino de ciências e educação ambiental. In: ENCONTRO NACIONAL DE PESQUISA EM EDUCAÇÃO EM CIÊNCIA, 5., 2005, Bauru. Atas... Bauru, 2005. 1 CD-ROM.

Geologia/Geociências no Ensino Fundamental e a formação de professores.

Revista do Instituto de Geociências Usp, São Paulo, v. 3, p. 13-30, 2005 b.

- A narrativa histórica das geociências no Ensino Fundamental (EGB): um exemplo com o tema "A formação do Universo". Enzeñanza de las Ciencias de la Tierra, Girona, v. 4, n. extra, p. 64-69, 1996a.

Fieldwork teaching and the in-service training of primary/secondary school science teachers in Brazil. In: STOW, D.A.V.; McCALL, G. J. H. (Eds.). Geoscience education and training: in schools and universities, for industry and public awareness. Rotterdam: A. A. Balkema Pub., 1996b. p. 329-340.

Geologia pra que te quero no ensino de ciências. Educação \& Sociedade, Campinas, n. 36, p. 100-117, 1990.

COMPIANI, M.; CARNEIRO, C. D. R. Os papéis didáticos das excursões geológicas. Enzeñanza de las Ciencias de la Tierra, Madrid, v. 1, n. 2, p. 90-98, 1993. 
O lugar e as escalas e suas dimensões ...

.; FIGUEIRÔA, S. F. M; GONÇALVES, P. W.; et al. Parceria entre universidade e escola pública para a formação continuada de professores do Ensino Fundamental com temas de geociências. In: ENCONTRO NACIONAL DE PESQUISA EM ENSINO DE CIÊNCIAS, 3., 2001, Atibaia. Anais... Atibaia, 2001. CD-ROM.

DA COSTA, L. A. M.; INDA, H. A. V. Fundamentos da Geologia pós-moderna. Sâo Paulo: CPRM, 1992. (Série Sinopses).

DUBOIS, P. Correio Popular, Campinas, 19 nov. 2000. Caderno Ciência. [entrevista].

FRODEMAN, R. Geological reasoning: geology as an interpretive and historical science. GSA Bulletin, Washington, v. 107, n. 8, p. 960-968, 1995.

GALLO, S. Transversalidade e educação: pensando uma educação não disciplinar. 2. ed. In: ALVES, N. (Org.). O sentido da escola. Rio de Janeiro: DP\&A, 2000. p. 17-41.

KINCHELOE, J. L. A formação do professor como compromisso político: mapeando o pós-moderno. Porto Alegre: Artes Médicas, 1997.

LEVESON, D. J. The geologist's vision. J. Geological Education, Bellingham, v. 36, p. 306-309, 1988.

LACREU, H. Las geociencias en la alfabetización científica. In: KAUFMAN, M.;

FUMAGALLI, L. (Comp.). Enseñar ciencias naturales. Buenos Aires: Paidós, 1999. p. 239-270.

NEWERLA, V. B. Deslizamentos: um mal inevitável? Ciência \& Ensino, Campinas, n. 6, p. 13-17, 1999.

PASCHOALE, C. Geologia como semiótica da natureza. São Paulo, 1989. Dissertação (Mestrado) - Pontifícia Universidade Católica de São Paulo.

PONTUSCHKA, N. N. Ousadia no diálogo: interdisciplinariedade na escola. São Paulo: Loyola, 1993.

SÁNCHEZ, M. A. Construindo conceitos, aplicando procedimentos e estimulando atitudes no campo: as enchentes em 1999 no Estado Vargas, Venezuela. Campinas, 2000. Dissertação (Mestrado) - Instituto de Geociências, Universidade Estadual de Campinas.

SUERTEGARAY, D. M. A. Geografia e trabalho de campo. In: COLÓQUIO: O DISCURSO GEOGRÁFICO NA AURORA DO SÉCULO XXI, 1996, Florianópolis. Anais... Florianópolis, Programa de Pós Graduação em Geografia - UFSC, 1996. p. 1-11.

ZABALA, A. El enfoque globalizador. Cuadernos de Pedagogía, Madrid, n. 168, p. 22-27, 1989.

Artigo recebido em agosto de 2006 e aceito em fevereiro de 2007. 